\title{
SOME STABILITY RESULTS RELATED TO SOME FIXED POINT THEOREMS
}

\author{
Mihai Monea And Dan ŞTefan Marinescu
}

Abstract. In this paper, we introduce two types of stability and we investigate some fixed point theorems, as Schauder Theorem, Borsuk Theorem and Knaster Lemma, from this viewpoint.

Mathematics subject classification (2010): 39B82, 37C25.

Keywords and phrases: fixed point, stability, Contraction Principle, Schauder Theorem, Borsuk Theorem, Knaster Lemma.

\section{REFERENCES}

[1] C AlsinA AND R. GER, On some inequalities and stability results related to the exponential function, J. Inequal. Appl., 2 (1998), 373-380.

[2] Sz. ANDrÁs AND A. R. MÉzÁros, Ulam-Hyers stability of dynamic equations on time scales via Picard operators, Appl. Math. Comput., 219, 9 (2013), 4853-4864.

[3] V. BERINDE, On the stability of fixed point procedure, Bul. Ştiinţ. Univ. Baia Mare, Ser. B, Matematică-Informatică, 18, 1 (2002), 7-14.

[4] M. Bota, E. Karapinar And O. MLeşniţe, Ulam-Hyers stability results for fixed point problems via $\alpha-\psi$-contractive mapping in (b)-metric space, Abstr. Appl. Anal., 2013 (2013), Article ID 825293

[5] J. BRZDȨK, L. CĂDARIU AND K. CiePlińs Ki, Fixed Point Theory and the Ulam Stability, J. of Func. Spaces, 2014 (2014), Article ID 829419, http://dx.doi.org/10.1155/2014/829419.

[6] P. GĂ VRuţA, S.-M. Jung AND Y. Li, Hyers-Ulam stability of mean value points, Ann. Funct. Anal., 1, 2 (2010), 68-74.

[7] A. Granas And J. Dugundu, Fixed Point Theory, Springer-Verlag, New York, 2003.

[8] D.H. HyERS, On the stability of the linear functional equation, Proc. Nat. Acad. Sci. USA, 27 (1941), 222-224.

[9] S. -M. JUnG, Hyers-Ulam-Rassias Stability of Functional Equations in Nonlinear Analysis, Springer, New York, 2011.

[10] Y. LI, Hyers-Ulam Stability of Linear Differential Equations $y \prime \prime=\lambda^{2} y$, Thai Journal of Mathematics, 8 (2010), 215-219.

[11] C. Mortici, M. Th. Rassias And S.-M. Jung, On the stability of a functional equation associated with the Fibonacci numbers, Abstr. Appl. Anal., 2014 (2014), Article ID 546046.

[12] C. Mortici, M. MoneA AND D. Ş. Marinescu, The stability of some points arising from continuous, differential and integral expressions, Monatsh. Math., 180, 1 (2015), 101-122, DOI: 10.1007/s00605-015-0779-7.

[13] M. S. Moslehian AND D. Popa, On the stability of the first-order linear recurrence in topological vector spaces, Non. Anal: Theory, Meth. \& Appl., 73, 9 (2010), 2792-2799.

[14] C. T. NGa And K. Nikodem, On approximately convex functions, Proc. Amer. Math. Soc., 118 (1993), 103-108.

[15] J. C. Parnami and H. L. Vasudeva, On the stability of almost convex functions, Proc. Amer. Math. Soc., 97 (1986), 67-70.

[16] B. E. RHOADES, Fixed point theorems and stability results for fixed point iteration procedures, Indian J. Pure Appl. Math., 21, 1 (1990), 1-9. 
[17] V. RADU, The fixed point alternative and the stability of functional equations, Fixed Point Theory, 4, 1 (2003), 91-96.

[18] I. A. Rus, Remarks on Ulam stability of the operatorial equations, Fixed Point Theory, 10, 2 (2009), 305-320.

[19] I. A. RUs, Ulam Stability of the Operatorial Equations, included in book: TH. M. RASSIAS, J. BRZDÉK (EDS.), Functional Equations in Mathematical Analysis, Springer, 2010, pp. 287-306.

[20] S.-E. TAKahasi, T. Miura And S. Miyajima, On the Hyers-Ulam stability of the Banach spacevalued differential equation $y^{\prime}=\lambda y$, Bull. Korean Math. Soc., 39 (2002), 309-315.

[21] S. M. Ulam, Problems in Modern Mathematics, Chap. VI, Science Editions, Wiley, New York, 1964. 